\title{
Awareness and Vaccine Coverage of Hepatitis B among Cameroonian Medical Students
}

\author{
Desmond Aroke ${ }^{(D)},{ }^{1,2}$ Benjamin Momo Kadia ${ }^{(D)},{ }^{3,4}$ \\ Ephesians Nkwetta Anutebeh, ${ }^{5}$ Cluade Asaba Belanquale, ${ }^{6}$ Glory Masango Misori, ${ }^{2,5}$ \\ Alfred Awa, ${ }^{7}$ Clarence M. Mbanga, ${ }^{8}$ and Larry Tangie Ngek ${ }^{6}$ \\ ${ }^{1}$ Fontem District Hospital, Fontem, Cameroon \\ ${ }^{2}$ Health and Human Development (2HD) Research Network, Douala, Cameroon \\ ${ }^{3}$ Grace Community Health and Development Association (GRACHADA), Kumba, Cameroon \\ ${ }^{4}$ Faculty of Infectious and Tropical Diseases, London School of Hygiene and Tropical Medicine, London, UK \\ ${ }^{5}$ Faculty of Health Sciences, University of Buea, Buea, Cameroon \\ ${ }^{6}$ Faculty of Medicine and Biomedical Sciences, University of Yaoundé I, Yaoundé, Cameroon \\ ${ }^{7}$ Ndop District Hospital, Ndop, Cameroon \\ ${ }^{8}$ Mankon Sub-Divisional Hospital, Bamenda, Cameroon
}

Correspondence should be addressed to Desmond Aroke; arokedess@hotmail.com

Received 17 June 2018; Revised 27 August 2018; Accepted 9 September 2018; Published 25 September 2018

Academic Editor: Marcelo A. Soares

Copyright (C) 2018 Desmond Aroke et al. This is an open access article distributed under the Creative Commons Attribution License, which permits unrestricted use, distribution, and reproduction in any medium, provided the original work is properly cited.

\begin{abstract}
Background. The endemic nature of the hepatitis B virus (HBV) in Sub-Saharan Africa is a significant public health problem that places health care providers (medical students inclusive) at increased risk of occupational exposure. However vaccination against HBV is not systematic among medical students in Cameroon. Thus, we sought to evaluate awareness and HBV vaccine coverage among medical students in Cameroon. Methods. Using semistructured questionnaire and a cross-sectional approach, medical students from 3 State Universities in Cameroon were evaluated for their knowledge, attitudes, and vaccination status against the HBV. Data were collected over a 3-month period. HBV vaccine status was defined as complete (3 doses), partial (1 and 2 doses), and unvaccinated. Data were entered and analyzed using Epi-info 7. Results. There were 714 respondents among whom $186(26.05 \%)$ had been vaccinated at least once against HBV. Sixty-six (9.24\%) were partially vaccinated and $120(16.81 \%)$ completely vaccinated. No student had done postvaccination serologic testing to confirm full immunisation. Eighty-three percent (83.00\%) of respondents had adequate knowledge on HBV infection and vaccine, while $90.00 \%$ had adequate knowledge on HBV transmission. Most medical students had a positive attitude towards the HBV vaccine. The most common negative attitudes were worries about the side effects and fears of being infected by the vaccine. Conclusion. Despite adequate knowledge on HBV infection and vaccination only about 1 in 6 medical students had completed the HBV vaccination series. This highlights the need for better health policies aimed at increasing access and coverage of the HBV in at-risk populations like medical students.
\end{abstract}

\section{Background}

Hepatitis B virus (HBV) is a DNA virus of the family hepadnaviridae which could be responsible for acute and/or chronic pathology in the liver. Globally, two billion people (about one-third of the world's population) have serological evidence of prior HBV infection. An estimated 240 million people ( $4 \%$ of the world's population) are chronic HBV carriers, with about 780,000 deaths occurring yearly from
HBV related causes [1]. In Sub-Saharan Africa, HBV is highly endemic with a prevalence of $5-10 \%$. In Cameroon, HBV remains an important public health problem with a prevalence rate of about $8 \%$ [2].

HBV can be transmitted through percutaneous or mucosal exposure to infected blood and bodily fluids. Health care providers (HCP) and/or medical students have been shown to be four times more likely to contract the HBV than the general adult population [3].This is because the health 
TABLE 1: Definition of operational variables.

\begin{tabular}{ll}
\hline Score & Feature \\
\hline Knowledge on hepatitis B infection and vaccine & \\
$8-12$ of 12 correct responses & Good knowledge on signs and symptoms \\
$0-7$ of 12 correct responses & Poor knowledge on signs and symptoms \\
$5-7$ of 7 correct responses & Good knowledge on route of transmission \\
$0-4$ of 7 correct responses & Poor knowledge on route of transmission \\
Attitudes towards hepatitis $\mathbf{B}$ vaccine: & \\
$\geq 4$ ff 7 Positive attitudes & Positive attitude towards HBV vaccine \\
$\geq 3$ ff 6 Negative attitudes & Negative attitude towards HBV vaccine \\
HBV vaccine uptake & \\
3 & Complete vaccination \\
$1-2$ & Incomplete vaccination \\
0 & Not vaccinated \\
\hline HBV: Hepatitis B virus. &
\end{tabular}

care environment and the nature of their work increases their risk of being exposed to infection with blood-borne pathogens such as $\mathrm{HBV}$, hepatitis $\mathrm{C}$ virus (HCV), and human immunodeficiency virus (HIV) $[4,5]$. HBV is highly infectious and is 40 to 100 times more contagious when compared to HIV [6]. HBV can remain stable on environmental surfaces for up to 7 days. It is thus the greatest threat of infection for HCP [7].

HBV infection can be prevented by following a simple and available vaccination schedule [8]. HBV vaccine is the first anticancer vaccine which has outstanding record of safety and effectiveness. It is $95 \%$ effective in preventing children and adults from developing chronic infection [1]. More so, routine vaccination of HCPs in the United States of America (USA) has been demonstrated to decrease the incidence of HBV [911]. Despite the high prevalence of $\mathrm{HBV}$ and effectiveness of the vaccine, there is no policy on routine vaccination of HCPs in Cameroon. The Cameroon government in a bit to reduce the high prevalence of $\mathrm{HBV}$ since 2004 systematically provides HBV vaccine to all infants as an integral part of the Expanded Programme of Immunisation at 6 weeks, 10 weeks, and 14 weeks [12]. However, this measure fails to protect the exposed adult population. Awareness of transmission routes, risk involved in treatment procedures, and implementation of appropriate precautions when treating patients are critical in preventing the spread of this infection. We therefore set to evaluate the knowledge of $\mathrm{HBV}$, attitudes towards $\mathrm{HBV}$ vaccine, and vaccine coverage of $\mathrm{HBV}$ vaccine among medical students.

\section{Methods}

2.1. Study Design, Setting, and Participants. This was a descriptive cross-sectional survey carried out over a period of 3 months (August 2016 - November 2016) among students in Faculty of Health Sciences of the Universities of Buea and Bamenda and the Faculty of Medicine and Biomedical Sciences of the University of Yaoundé I. Medical schools were randomly chosen while recruitment of participants in each medical school was by convenient sampling. A medical student from each medical school was contacted by the principal investigator and trained on data collection procedure. In each medical school, the data collector visited each classroom during break, approached participants, and proposed the study. Participants who were present on days of the study and who gave written consent to participate in the study were recruited. Participants were approached and explained the nature and purpose of the study. Participants with a known positive hepatitis B status were excluded from the study. Description of this cross-sectional survey was based on the STROBE statement [13].

2.2. Ethical Considerations. The study received ethical approval from the Institutional Review Board of the Faculty of Health Sciences of the University of Buea. Consent forms were signed by students who agreed to participate in the study. Confidentiality was ensured during the study.

2.3. Data Collection. A pretested semistructured pen and paper questionnaire was given to each participant to fill. Data were collected on sociodemographic characteristics, knowledge on routes of transmission and signs and symptoms of $\mathrm{HBV}$ infection, attitudes, and practices towards hepatitis B vaccine.

2.4. Definition of Operational Terms and Variables. Scores of $\geq 8 / 12$ and $\geq 5 / 7$ on correct knowledge defined adequate knowledge on HBV infection and vaccine, and HBV transmission, respectively. A positive attitude was based on a score of $\geq 4$ of 7 positive attitudes while a negative attitude was based on a score of $\geq 3$ of 6 negative attitudes. HBV vaccine status was defined as complete (3 doses), partial (1 and 2 doses), and not vaccinated (zero dose). See Table 1.

2.4.1. Statistical Analysis. Data were entered and analyzed using Epi-info version 7 statistical software. Results are presented as counts (percentages), mean and standard deviation (SD), or median and interquartile range (IQR) as appropriate. 
TABLE 2: Sociodemographic characteristics of participants.

\begin{tabular}{lcc}
\hline Characteristic & N(total=714) & Percentage (\%) \\
\hline Sociodemographic & & 53.93 \\
Females & 784 & 98.04 \\
Single & 700 & $54.62(39.22)$ \\
FHS Buea (clinical year) & $390(280)$ & $23.81(12.61)$ \\
FHS Bamenda (clinical year) & $170(90)$ & $21.67(10.92)$ \\
FMBS Yaoundé I (clinical year) & $154(78)$ & 37.18 \\
Basic sciences & 266 & 62.82 \\
Clinical year & 448 & \\
\hline
\end{tabular}

$\mathrm{N}$ : Number of participants with the available information on the variable, FHS; Faculty of Health Sciences, FMBS; Faculty of Medicine and Biomedical Sciences.

\section{Results}

3.1. Sociodemographic Characteristics. During the study period 758 medical students were approached while 714 medical students accepted to participate in the study. The retention rate was $94.20 \%$. The mean age (SD) of participants was $22.03( \pm 1.1)$ years. Other characteristics are summarised in Table 2.

3.2. Rate of $H B V$ Vaccine Uptake. Of 714 participants, 186 (26.05\%) had been vaccinated at least once against HBV. Of these, $28(3.92 \%)$ had been administered only the $1^{\text {st }}$ dose, 38 (5.32\%) had received 2 doses, and 120 (16.81\%) had received all 3 doses. Of the 186 students vaccinated at least once 102 (54.84\%) were clinical year students and of the 120 who had completed vaccination $86(71.67 \%)$ were in the clinical years. The complete vaccine uptake rate among clinical year students was $19.20 \%$ and among basic sciences students was $12.70 \%$. Sixty-two (15.90\%), 26 (15.29\%), and 32 (20.78\%) students of the medical schools of the universities of Buea and Bamenda and Yaoundé I, respectively, had been completely vaccinated.

3.3. Knowledge on $\mathrm{HBV}$ and Vaccine Uptake. Correct scores ranged from 3 to 12 with a mode of 9 correct scores. $83 \%$ of our participants had adequate knowledge on HBV infection and vaccine. $93 \%$ of participants correctly responded that health care providers can spread the infection to patients and $89 \%$ accepted that patients can spread the infection to them. Correct scores on HBV transmission ranged from 0 to 7 with a mode of 6 correct scores. $90 \%$ of our participants had adequate knowledge on HBV transmission. Also, 92\% of respondents correctly responded that transmission was possible through broken skin in contact with contaminated blood. Table 3 summarises responses to questions asked on HBV infection and vaccine.

3.4. Attitudes towards $H B V$ and Vaccine Uptake. As shown on Table 4, most medical students had a positive attitude towards the HBV vaccine. The vaccine was available in a third of their work places. The main negative attitudes towards the vaccine were worries about the adverse effect $(48.99 \%)$ and being afraid of infection from the vaccine (39.31\%).

\section{Discussion}

Medical students are well known to be at increased risk of contracting HBV [14-16]. This study is one of the few studies in Cameroon that assessed the knowledge and vaccine coverage of medical students in state medical schools. It appears that medical students had a good knowledge on HBV infection, routes of transmission, and vaccine. Despite this awareness only 1 in 6 medical students had received the complete HBV vaccine and none of those vaccinated had done the postvaccination antibody titres to confirm immunisation. The vaccination uptake was understandably higher among clinical year students. The low rate of vaccine uptake was due to unavailability of the vaccine and possibly lack of policies.

Only one-quarter of the respondents had ever taken an HBV vaccine, and among all respondents, only about 1 in 6 had received the complete vaccine. Although most respondents had an appropriate knowledge on HBV infection, routes of transmission, and the vaccine, the vaccine coverage was low. Unavailability of the vaccine in most hospitals and lack of a clear policy on HBV vaccination in medical schools could in part explain the low vaccine coverage. Also some respondents had negative attitudes towards the vaccine which included worrying about side effects and risk of infection. $\mathrm{HBV}$ is a major public health concern and being one of the most contagious blood-borne infections should be given utmost attention. The $16.8 \%$ complete vaccination rate among our respondents is alarming given their increased risk of contracting HBV. Though similar vaccine uptake rates have been reported in India and Cameroon, these studies were done among first-year students and using smaller sample sizes $[17,18]$. Much higher rates have been obtained in Nigeria, Bangladesh, Pakistan, and Brazil where there are more organised and structured programs to encourage uptake of the vaccine $[16,19-21]$. Urgent measures are therefore required to put in place policies that will encourage vaccination coverage among students.

The Advisory Committee on Immunisation Practices (ACIP) has since 1997 recommended postvaccination serologic testing at least $1-2$ months following last dose of vaccine to confirm immunity [15]. Previous studies among medical students have reported postvaccination serologic testing rates of $10-65 \%[18,21,22]$. It is intriguing that none of our 
TABLE 3: Knowledge on hepatitis B virus infection and vaccine.

\begin{tabular}{|c|c|c|c|}
\hline Characteristic & Yes $(\%)$ & No $(\%)$ & Don't know (\%) \\
\hline \multicolumn{4}{|l|}{ Knowledge on HBV and Vaccine } \\
\hline HBV can be caused by bacteria $(\mathrm{N}=706)$ & $24(3.40)$ & $674(95.47)$ & $8(1.13)$ \\
\hline $\mathrm{HBV}$ is contagious $(\mathrm{N}=708)$ & $552(77.97)$ & $138(19.49)$ & $18(2.54)$ \\
\hline HBV carrier may look healthy without showing any symptoms of the disease $(\mathrm{N}=712)$ & $628(88.20)$ & $46(6.46)$ & $38(5.34)$ \\
\hline HBV can be lethal $(\mathrm{N}=712)$ & $670(94.10)$ & $32(4.49)$ & $10(1.40)$ \\
\hline Patients can spread HBV to health care workers $(\mathrm{N}=710)$ & $660(92.96)$ & $34(4.79)$ & $16(2.25)$ \\
\hline Health care workers can spread HBV to patients $(\mathrm{N}=704)$ & $630(89.49)$ & $42(5.97)$ & $32(4.55)$ \\
\hline $\mathrm{HBV}$ vaccination is not for all people $(\mathrm{N}=700)$ & $172(24.57)$ & $482(68.86)$ & $46(6.57)$ \\
\hline HBV vaccination does not cause hepatitis $(\mathrm{N}=700)$ & $456(65.14)$ & $190(27.14)$ & $54(7.71)$ \\
\hline HBV vaccination can prevent hepatitis $(\mathrm{N}=708)$ & $668(94.35)$ & $30(4.24)$ & $10(1.41)$ \\
\hline HBV vaccination does not increase the risk for complications $(\mathrm{N}=698)$ & $498(71.35)$ & $106(15.19)$ & $94(13.47)$ \\
\hline $\mathrm{HBV}$ vaccination is contraindicated in pregnancy $(\mathrm{N}=700)$ & $186(16.57)$ & $240(34.29)$ & $274(39.14)$ \\
\hline The HBV vaccine has 3 doses $(\mathrm{N}=694)$ & $474(68.30)$ & $28(4.03)$ & $192(27.67)$ \\
\hline \multicolumn{4}{|l|}{ Knowledge on route of transmission of $\mathrm{HBV}$} \\
\hline Broken skin in contact with saliva contaminated with blood of HBV pos patient $(\mathrm{N}=706)$ & $636(90.08)$ & $38(5.38)$ & $32(4.53)$ \\
\hline Broken skin in contact with blood of $\mathrm{HBV}$ pos patients $(\mathrm{N}=710)$ & $650(91.55)$ & $36(5.07)$ & $24(3.38)$ \\
\hline Broken skin in contact with saliva of HBV pos patients $(\mathrm{N}=696)$ & $484(69.54)$ & $138(19.38)$ & $74(10.63)$ \\
\hline Intact skin with $\mathrm{HBV}$ pos patient $(\mathrm{N}=702)$ & $78(11.11)$ & $562(80.06)$ & $62(8.83)$ \\
\hline Intact skin with intact skin of $\mathrm{HBV}$ pos patient $(\mathrm{N}=704)$ & $86(12.22)$ & $564(80.11)$ & $54(7.67)$ \\
\hline Needle stick injury $(\mathrm{N}=698)$ & $584(83.67)$ & $64(9.17)$ & $50(7.16)$ \\
\hline Aerosol produced by a hand piece $(\mathrm{N}=688)$ & $94(13.66)$ & $394(57.27)$ & $200(29.07)$ \\
\hline
\end{tabular}

$\mathrm{N}$ : Number of participants with the available information on the variable, HBV: hepatitis B virus, pos: positive.

TABLE 4: Positive and negative attitudes towards the hepatitis B vaccine.

\begin{tabular}{lc}
\hline Characteristic & Yes (\%) \\
\hline Positive attitudes & $608(88.12)$ \\
I am at risk because of the nature of my work $(\mathrm{N}=690)$ & $584(84.39)$ \\
Vaccination prevents spread of infection to patients $(\mathrm{N}=692)$ & $634(90.83)$ \\
Vaccination protects my family members $(\mathrm{N}=698)$ & $678(97.13)$ \\
Hepatitis B is a serious disease $(\mathrm{N}=698)$ & $650(93.12)$ \\
Hepatitis vaccine is effective in preventing the disease $(\mathrm{N}=698)$ & $201(29.41)$ \\
the vaccine is available at my work place $(\mathrm{N}=680)$ & $626(90.72)$ \\
the risk of death among vaccinated persons is reduced compared to the non vaccinated $(\mathrm{N}=690)$ & $338(48.99)$ \\
Negative attitudes & $66(9.62)$ \\
I am worried about its adverse effects $(\mathrm{N}=690)$ & $114(16.52)$ \\
I am afraid of infection $(\mathrm{N}=692)$ & $110(15.99)$ \\
It is not effective in disease protection $(\mathrm{N}=686)$ & $144(22.45)$ \\
I am not at high risk of contracting HBV $(\mathrm{N}=690)$ & \\
The vaccine is not available $(\mathrm{N}=688)$ &
\end{tabular}

$\mathrm{N}$ : Number of participants with the available information on the variable.

participants had measured antibody titres after vaccination. This is possibly because most people are unaware of the existence of the test and unavailability of the test in most tertiary centres of health care.

It is of paramount importance for medical students to be properly informed on HBV so as to protect themselves and their potential patients. Also they are in frequent contact with the general population and are thus expected to know and promote measures to immunise the general public. Generally, most (83\%) medical students had a good knowledge on HBV infection and vaccination. However on a closer look it was disturbing to find out that up to 156 (22\%) medical students did not know HBV is contagious. Majority of these students were in the preclinical years and they were possibly awaiting lectures on HBV.

Health care providers, who are often in frequent contact with blood and other body fluids, are well known to be at increased risk of contracting blood-borne infections such 
as $\operatorname{HBV}[9,23]$. Ninety and ninety-three percent of our respondents knew that health care workers could spread HBV to patients and vice versa, respectively. Though a majority of the students were aware of this risk, it is still unacceptable for some medical students to be unaware. We advocate for a hundred percent awareness prior to starting clinical rotations.

Taking the vaccine and encouraging others to take the vaccine properly require adequate knowledge on vaccine and its doses. Only $68 \%$ of our respondents correctly pointed out to the fact that the vaccine had 3 doses. This is most likely because a majority of respondents did not have the vaccine in their facilities and had not taken the vaccine.

Most respondents had appropriate knowledge on the routes of transmission of HBV. This could in a bit explain the low vaccine coverage as some respondents will turn to believe that protecting themselves against these modes of contracting the virus is less costly and sufficient.

Majority of the respondents like in other studies [24] reported having a positive attitude towards the $\mathrm{HBV}$ vaccine because they believe HBV is a serious disease and that the vaccine is effective in preventing the disease. This could be accounted for by the fact that attitudes are usually greatly affected by knowledge. Thus the adequate knowledge on HBV will explain the positive attitudes by respondents. Despite positive attitudes, about one-half of the respondents were worried about the adverse effects of the vaccine while another $40 \%$ were worried about the risk of acquiring infection from the vaccine. These negative attitudes could partly explain the low vaccine coverage. Emphasis should thus be made during lectures on the safety of $\mathrm{HBV}$ vaccine and that it has no risk of infection.

Despite providing a trove of information on HBV infection and vaccination among Cameroon medical students, our study does have limitations that are usually associated with an observational design. First, our study included only state medical schools leaving out private medical schools. Thus, this might have failed to give a true representation of the vaccine coverage among Cameroonian medical students. Also, participants' responses to negative attitudes were restricted (by predefined answers) and therefore a limited array of factors impairing vaccine receptivity in the study population was explored. More so, knowledge and attitudes were assessed using a nonstandardized questionnaire. Convenient sampling and recall bias are also shortcomings observed in our study. However the multi-institutional design of our study and large sample size increase the validity of our study.

\section{Conclusion}

Despite adequate knowledge on HBV infection, vaccination, and routes of transmission only about 1 in 6 medical students had been completely vaccinated. This low rate of vaccination may be related to unavailability of the vaccine, lack of policies on mandatory $\mathrm{HBV}$ vaccination, and negative attitudes towards the vaccine. Given the high prevalence of hepatitis $B$ infection in Cameroon and the effectiveness of the HBV vaccine, eradication of this disease should be a public health priority. We recommend vaccination of those at high risk of exposure and transmission (medical students) as a first step towards eradicating this disease. This can be achieved by making the vaccine readily available and at affordable prices or free to all medical schools and hospitals. Medical school authorities should strive for 100 percent awareness among medical students and implement mandatory vaccination against HBV.

\section{Abbreviations \\ HBV: Hepatitis B virus \\ HCV: Hepatitis C virus \\ HCP: Health care professionals \\ HIV: Human immunodeficiency virus \\ USA: United States of America \\ WHO: World Health Organization.}

\section{Data Availability}

The data used to support the findings of this study are available from the corresponding author upon request.

\section{Ethical Approval}

This study was approved by the Institutional Review Board of the Faculty of Health Sciences of the University of Buea.

\section{Consent}

Written informed consent was obtained from all participants.

\section{Conflicts of Interest}

All authors declare they have no conflicts of interest.

\section{Authors' Contributions}

Desmond Aroke was responsible for conception and design of the study, data collection, data analysis, drafting, and reviewing of the manuscript. Ephesians Nkwetta Anutebeh, Cluade Asaba Belanquale, Glory Masango Misori, Alfred Awa, Clarence M. Mbanga, and Benjamin Momo Kadia were responsible for guiding study design, data collection, and review of the manuscript. Larry Tangie Ngek was responsible for critical review of the manuscript and provided intellectual guidance. All the authors approved the submission of the final manuscript.

\section{Acknowledgments}

The authors are grateful to medical students who amidst their busy schedule took out time to participate in this study. The 2HD Research Network is supported by a Cruddas Link Fellowship to SPC (Tseu Medical Institute, Harris Manchester College, University of Oxford, UK). 


\section{References}

[1] World Health Organisation, "Hepatitis B. media centre," in Fact Sheet, vol. 204, 2015.

[2] A. Amazigo UO chime, "Hepatitis B virus infection in rural and urban populations of Eastern Nigeria, prevalence of serological markers," East Afr Med J, vol. 67, no. 8, pp. 539-544, 1990.

[3] E. B. Byrne, "Viral hepatitis: An occupational hazard of medical personnel. Experience of the Yale-New Haven Hospital," Journal of the American Medical Association, vol. 195, pp. 362-364, 1966.

[4] A. Pruss-Ustün, E. Rapiti, and Y. Hutin, "Estimation of the global burden of disease attributable to contaminated sharps injuries among health-care workers," American Journal of Industrial Medicine, vol. 48, no. 6, pp. 482-490, 2005.

[5] R. Gambhir, V. Kapoor, G. Jindal, S. Garg, S. Setia, and S. Setia, "Attitudes and awareness regarding Hepatitis B and Hepatitis C amongst health-care workers of a tertiary Hospital in India," Annals of Medical and Health Sciences Research, vol. 3, no. 4, pp. 551-558, 2013.

[6] CDC, Hepatitis B Virus, https://www.cdc.gov/vaccines/pubs/ pinkbook/downloads/hepb.pdf.

[7] L. A. S. Ciorlia and D. M. T. Zanetta, "Hepatitis B in healthcare workers: prevalence, vaccination and relation to occupational factors," Brazilian Journal of Infectious Diseases, vol. 9, no. 5, pp. 384-389, 2005.

[8] P. Van Damme and J. W. Ward, "Hepatitis B Vaccines," in Plotkin's Vaccines, pp. 342-374, Elsevier, 2018, http://linkinghub .elsevier.com/retrieve/pii/B9780323357616000250.

[9] L. A. Moyer and E. E. Mast, "Hepatitis B and the health care worker CDC answers frequently asked questions about how to protect health care workers," Immun Action Coalit, vol. 50, no. 651, pp. 1-2, 2001.

[10] Center for Disease Control and Prevention. A comprehensive immunization strategy to eliminate transmission of hepatitis B virus infection in the United States: Recommendations of the Advisory committee on Immunization Practices (ACIP), Part 2: Immunization of adults. MMWR Recomm Rep. vol. 55, no. RR-16, 2006.

[11] C. W. Shepard, E. P. Simard, L. Finelli, A. E. Fiore, and B. P. Bell, "Hepatitis B virus infection: epidemiology and vaccination," Epidemiologic Reviews, vol. 28, no. 1, pp. 112-125, 2006.

[12] Ministry of Public Health Cameroon, Plan For The Introduction of the Viral Hepatitis B Vaccine into the Routine EPI 2005-2009, pp. 1-22, 2004.

[13] E. Von Elm, D. G. Altman, M. Egger et al., "The strengthening the reporting of observational studies in epidemiology (STROBE) statement: guidelines for reporting observational studies," Bulletin of the World Health Organization, vol. 85, no. 11, pp. 867-872, 2007.

[14] K. A. Sepkowitz, "Occupationally acquired infections in health care workers: Part II," Annals of Internal Medicine, vol. 125, no. 11, pp. 917-928, 1996.

[15] CDC., "Immunization of health-care workers: recommendations of the Advisory committee on immunization practices (ACIP) and the hospital infection control practices advisory committee (HICPAC)," in MMWR, vol. 46, RR-18 edition, 1997.

[16] N. Paul and O. Peterside, "Hepatitis B vaccination rate among medical students at the university of port harcourt teaching hospital (Upth)," World Journal of Vaccines, vol. 14, pp. 1-7, 2015.

[17] M. Giri, J. Panda, and A. Sahoo, "Hepatitis B awareness and vaccination status among first year medical students," International
Journal of Community Medicine and Public Health, vol. 3, no. 2, pp. 530-532, 2016.

[18] J. J. N. Noubiap, J. R. N. Nansseu, K. K. Kengne, S. Tchokfe Ndoula, and L. A. Agyingi, "Occupational exposure to blood, hepatitis B vaccine knowledge and uptake among medical students in Cameroon," BMC Medical Education, vol. 13, no. 1, 2013.

[19] M. S. Akhter, A. Rizwan, and M. Wahiduzzaman, "Vaccination status and awareness of Hepatitis B among undergraduate medical students of two medical colleges in Bangladesh," Medicine Today, vol. 28, no. 1, pp. 27-29, 2016.

[20] M. Asif, C. Medicine, and M. M. College, "Hepatitis B vaccination coverage in medical students at a medical college of Mirpurkhas," JPMA, vol. 61, no. 680, pp. 1-5, 2011.

[21] E. P. de Souza and M. de S. Teixeira, "Hepatitis B Vaccination coverage and postvaccination serologic testing among medical students at a public university in Brazil," Rev Inst Med Trop Sao Paulo, vol. 56, no. 4, pp. 307-311, 2014, http://www.scielo.br/scielo .php?script=sci_arttext\&amp;pid=S0036-46652014000400307\& amp;lng=en\&amp; tlng=en.

[22] A. A. Acchammachary, M. Ubale, D. D. Belurkar, P. P. Bhave, A. A. Malgaonkar, and S. Kartikeyan, "A cross-sectional study of post-vaccination anti-HBs titer and knowledge of hepatitis B infection amongst medical students in a metropolitan city," International Journal of Research in Medical Sciences, vol. 5, no. 1, pp. 83-88, 2017.

[23] S. Ngekeng, A. Chichom-Mefire, P. Nde et al., "Hepatitis B prevalence, knowledge and occupational factors among health care workers in fako division, south west region Cameroon," Microbiology Research Journal International, vol. 23, no. 4, pp. 1-9, 2018.

[24] A. Mariam and J. B. Khayrat Al-Mousa, Knowledge, Attitude, and Practice of $\mathrm{HBV}$ vaccination among dentists in primary health care, dental centers and Kuwait university dental clinics, 2013. 


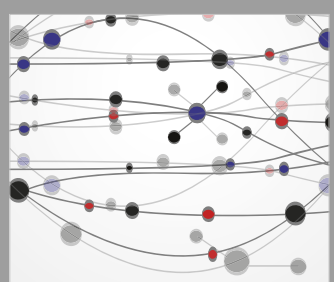

The Scientific World Journal
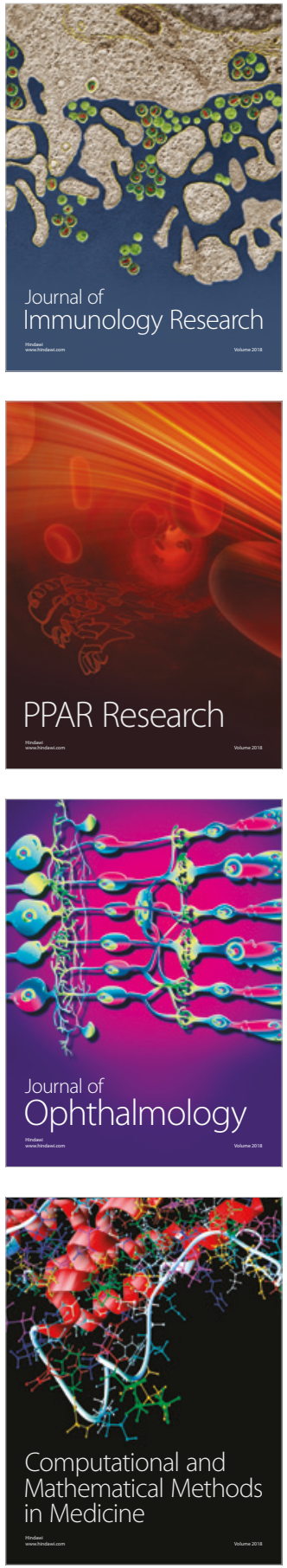

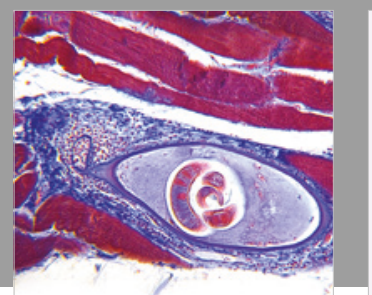

Gastroenterology Research and Practice

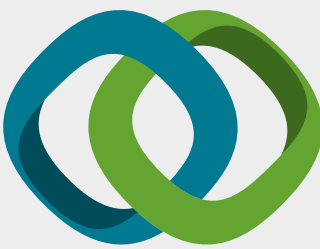

\section{Hindawi}

Submit your manuscripts at

www.hindawi.com
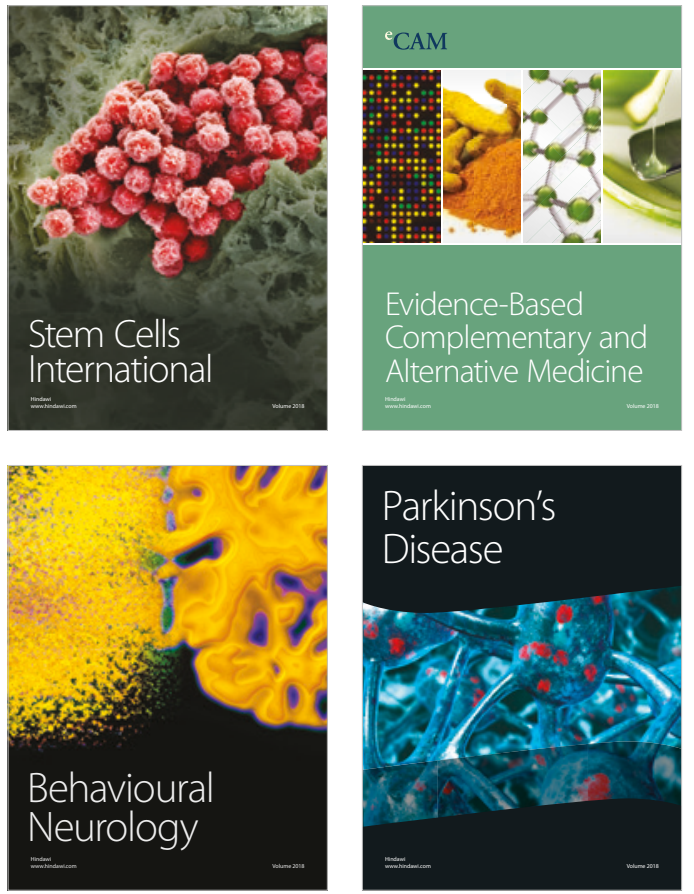

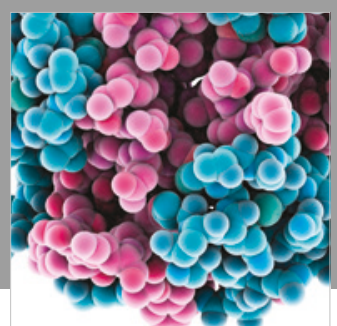

ournal of

Diabetes Research

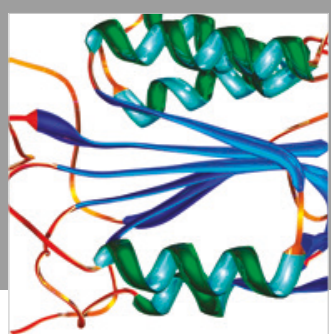

Disease Markers
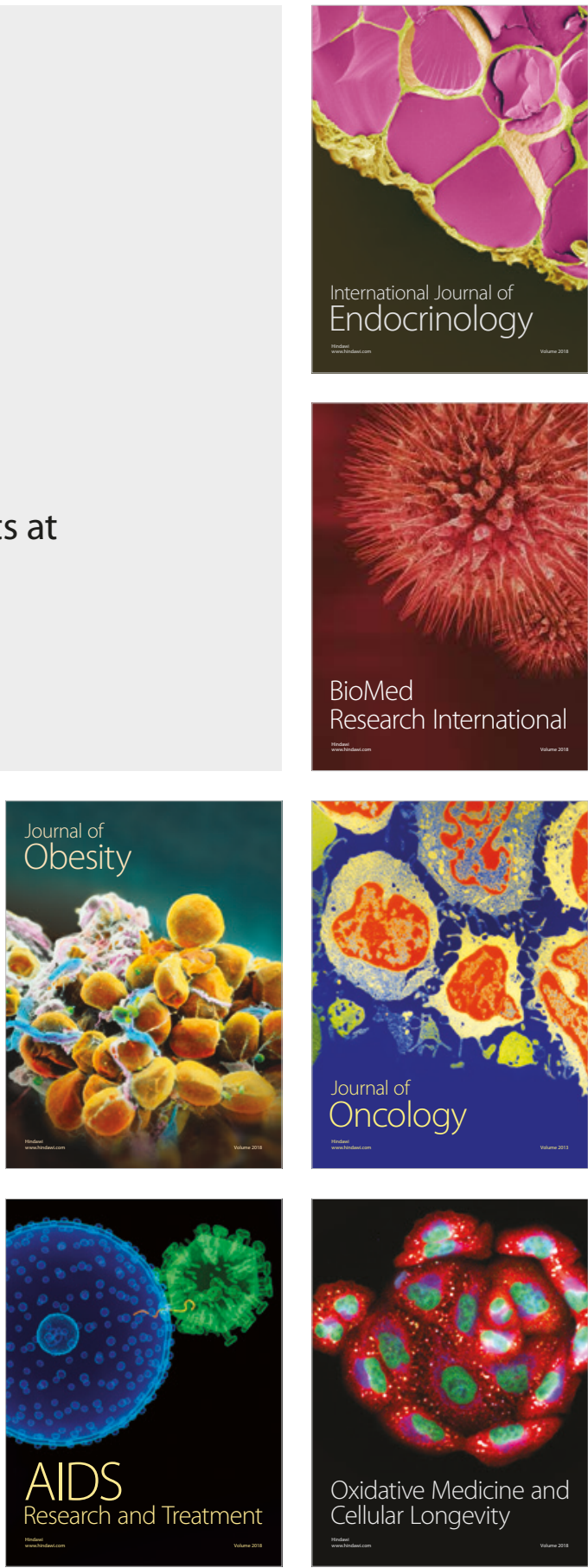